\title{
The Power of Education
}

\author{
VIRGINIA: IIIT, 2018. 25 PAGES. \\ JEREMY HENZELL-THOMAS
}

Education is one of the most valued assets of modernity, frequently deemed to be the foundation of a healthy society. However, despite this established human right that has been made increasingly accessible due to technological advancements such as the internet, there is an ethical and moral decline reflected in different aspects of our society. Jeremy Henzell-Thomas published a brief IIIT paper titled "The Power of Education" arguing that the true purpose of education has been forgotten. He seeks an engaging examination of what education fundamentally is and the powerful results a multidisciplinary education yields.

This paper is part of a project named Advancing Education in Muslim Societies (AEMS) and follows a series of works concerned with current issues impacting education. Jeremy Henzell-Thomas is a Research Associate at the Centre of Islamic Studies at the University of Cambridge and an Associate Editor of Critical Muslim, bringing with him years of experience on education and pedagogy in varying socio-cultural contexts. This paper is a critical read for all educators and life-long students, as it explores the essence of education and its importance in progressing human condition and society at large. 
Henzell-Thomas evaluates different topics pertaining to education in nine different subtopics. He brilliantly presents a strong case for developing a contemporary educational methodology that sustains short-term and long-terms effects. The first section ("Socrates and the Power of Questioning") examines the fate of Socrates upon questioning the status quo and what is entailed by commitment to lifelong learning seeking wisdom and truth. He argues that the Qur'an and the Prophet Muhammad affirm that societal and global transformation are reliant on personal transformation. Education should teach how to examine and transform the self in order to contribute to societal transformation.

The second section, titled "Open Inquiry and Lifelong Learning," examines the importance of seeking the truth through inquiry and lifelong learning that require the seeker to be open minded. Henzell-Thomas draws attention to contemporary polarity, fragmentation, and conflicts, along with multitude of other crises caused by tribalism, exclusivism, and identity politics. There is a failure to see the interconnectedness of all things, he argues in the third section titled "Wholeness, Fragmentation, and Self-Transformation." Bell, Bohm, and Blake suggested that our societal unity is linked in our interconnectedness and to understand this will lay the path to distancing ourselves from identity politics, tribalism, and focus on resolving chaotic conflicts.

He extends his argument on the importance of furthering independent inquiry and curiosity rooted in human consciousness and evolving knowledge in the fourth section, titled "The Expanding Horizon of Human Knowledge." Expansion of knowledge that relies on a multidisciplinary approach, cross-cultural exchange, and scientific methodology will lead the way to social progress. HenzellThomas defines a good education as one in which the goal is to seek knowledge of God. This is an important section as he highlights the goal of an education is to connect the two realms-physical and spiritual-by the way of ethical and spiritual values, objectives that drive us for the love of God. 
Henzell-Thomas examines the power of diversity through the religious and biological lenses in the sixth section, titled "Pluralism and Dynamic Outreach.” Modern human existence can be attributed to sustaining social networks through cultural and language exchange. He argues through examples found in the Qur'an that diversity and pluralism in all aspects — culture, language, race, religion - is willed by God and described by Prophet Muhammad to be a blessing. Pluralism should not be understood as tolerance of an 'other', he says, but rather an active process of engaging and fostering relationships; and an education that creates meaningful space for arts and humanities will allow for an enriched society.

The seventh section, titled "The Schooling Regime," digs into the current educational pedagogy dominated by teacher-centered transmission. Henzell-Thomas argues that the mainstream critique of indoctrination associated with religious education is flawed, when in reality indoctrination is embedded in the mainstream educational system preventing the development of critical thinking, curiosity, and reflection. He continues this argument against indoctrination, lack of dialogue, and poor engagement in the eighth section, titled "Narrative Fallacies, Conditioned Mindsets, Dichotomies, and Misperceptions." The objectives of education should be to examine conscious and subconscious biases; foster the curiosity to ask openended questions; tp acquire crossdisciplinary and multidisciplinary knowledge; and to resist holding tunnel vision 'truths'.

Henzell-Thomas draws to a close his argument that a truly qualitative education enables the human capacity, encompassing every realm of God's endowments to human beings, to yield ethical and mindful steps in one's inner development and transformation. The ninth section, titled "Realising Human Potential," emphasizes that the Quran repeatedly summons us to discern the truth and seek knowledge through a holistic education of which of its core is the awareness, consciousness and mindfulness of the omnipresence of God.

The final section, titled "Excellence with a Soul," argues that the mainstream education system has been creating excellence 
that is lacking in or even completely disconnected from character, ethics, morals, and spirituality. Examining higher education in America, Henzell-Thomas states that the institutions have long forgotten the goal of their establishment in helping individuals "to wrestle with deeper questions of meaning and purpose." He concludes that the higher education system around the globe has become increasingly concerned with creating cogs for machines and to gain recognition through the assimilation of one culture or worldview, rather than the collective global integration of cultures or worldviews.

The only drawback of this paper is that it left me wanting to read more about the essence of education. He passionately defines what education is, supporting his definition with arguments made by historical intellectuals along with Islamic scholarship and the Qur'an. An educational methodology that is multidisciplinary and crossdisciplinary with the ultimate goal of bettering humanity will be effective in treating contemporary ethical, moral, and social decay. The Power of Education makes a vital contribution to its current health by planting the seeds of hope: collectively, we all have the power to revive this ecosystem.

Madiha Patel

INDEPENDENT RESEARCHER

doi: 10.35632/ajis.v38i1-2.2945 